\title{
Impact of socio-economic status on the hospital readmission of Congestive Heart Failure patients: a prospective cohort study
}

\author{
Atefeh Noori ${ }^{1,2}$, Mostafa Shokoohi ${ }^{3,1}$, Mohammad Reza Baneshi ${ }^{1}$, Nasim Naderi ${ }^{4}$, Hooman Bakhshandeh $^{5}$, \\ Ali Akbar Haghdoost ${ }^{3,1, *}$
}

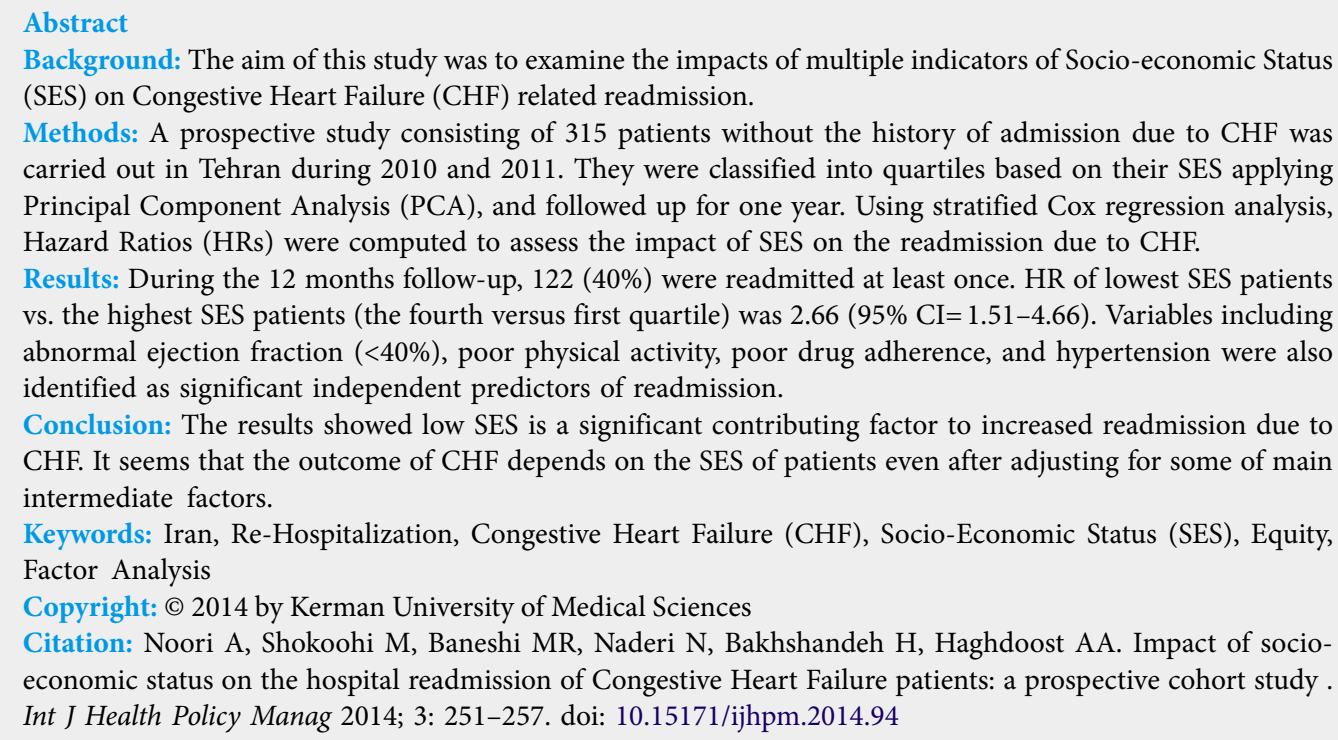

Background: The aim of this study was to examine the impacts of multiple indicators of Socio-economic Status (SES) on Congestive Heart Failure (CHF) related readmission.

Methods: A prospective study consisting of 315 patients without the history of admission due to CHF was carried out in Tehran during 2010 and 2011. They were classified into quartiles based on their SES applying Principal Component Analysis (PCA), and followed up for one year. Using stratified Cox regression analysis, Hazard Ratios (HRs) were computed to assess the impact of SES on the readmission due to CHF.

Results: During the 12 months follow-up, $122(40 \%)$ were readmitted at least once. HR of lowest SES patients vs. the highest SES patients (the fourth versus first quartile) was 2.66 (95\% CI=1.51-4.66). Variables including abnormal ejection fraction $(<40 \%)$, poor physical activity, poor drug adherence, and hypertension were also identified as significant independent predictors of readmission.

Conclusion: The results showed low SES is a significant contributing factor to increased readmission due to CHF. It seems that the outcome of CHF depends on the SES of patients even after adjusting for some of main intermediate factors.

Keywords: Iran, Re-Hospitalization, Congestive Heart Failure (CHF), Socio-Economic Status (SES), Equity, Factor Analysis

Copyright: @ 2014 by Kerman University of Medical Sciences

Citation: Noori A, Shokoohi M, Baneshi MR, Naderi N, Bakhshandeh H, Haghdoost AA. Impact of socioeconomic status on the hospital readmission of Congestive Heart Failure patients: a prospective cohort study . Int J Health Policy Manag 2014; 3: 251-257. doi: 10.15171/ijhpm.2014.94

Article History:

Received: 25 May 2014

Accepted: 24 September 2014

ePublished: 30 September 2014

\section{Key Messages}

Implications for policy makers

- Considering the fact that, the risk of readmission due to Congestive Heart Failure (CHF) in lowest Socio-Economic Status (SES) patients increased exponentially, some effective plans for these vulnerable groups may diminish high amounts of imposed costs.

- Optimizing education strategies in a manner to respect the patients' level of understanding; emphasizing the importance of medication adherence, diet and physical activity; increasing the self-monitoring skills as well as supporting the spouse and family members are considered as effective measures to prevent high readmission rate due to CHF.

- $\quad$ Adherence and managing other comorbidities had more effect in poor patients compared with upper SES patients. However, in upper SES patients there may be some other risk factors which need to be addressed.

Implications for public

The results of the current study showed that paying attention to alarming signs and symptoms and care about family members' education to comply with recommended drugs can prevent high readmission rate due to Congestive Heart Failure (CHF).

\section{Introduction}

Congestive Heart Failure (CHF) is a debilitating complaint associated with a large number of readmissions (1). A large body of research has revealed that CHF-related rehospitalisation within six months is around $25-30 \%$, which can increased to $40 \%$ within 1 year (2-4). In Iran, the rate of CHF reported 3500 per hundred thousand annually, which forms one of the major types of Cardiovascular Diseases (CVDs), held as the most important cause of death (5).

Previous studies had documented that the Socio-economic Status (SES) of CHF patients was a crucial indicator, which might influence the patient's behavioural pattern, environmental exposures, and access to healthcare services (6). There is little evidence in Middle East countries include Iran about the association of SES and readmission due to CHF. Nevertheless, recently one study was evaluated the association of education and occupation as SES indicators with CVD risk factors in Isfahan (7). It is reported that there is an association among SES and CVD risk factors; However, this is not indicated its impact on the CHF readmission. Besides, using only education or income as SES indicator has its own limitations such as the interaction between these classic 
meters of SES, and the issue of co-linearity among predictors $(6,8)$. To deal with these limitations, it is recommended to compute a weighted score of predictors and other principal assets using Principal Component Analysis (PCA) (9).

Taking into account the aforementioned potential role of SES in the risk of rehospitalisation due to $\mathrm{CHF}$, and the relatively high prevalence of this disease in Iran, this study aimed to measure the SES and its effect on the readmission rate of CHF patients for the first time in Iran using PCA. It is assumed that the result of this first study could contribute to providing the evidences for better understanding of association of combined wealth index and readmission due to CHF specifically in Iranian patients; also it is probable that it would be useful for other developing countries with similar circumstance to Iran.

\section{Methods}

This prospective study recruited 315 patients with the diagnosis of CHF according to the heart failure society of America guidelines (10) who were admitted for the first time (de novo acute heart failure) to the Shahid-Rajaee Cardiovascular and Research Center, a tertiary center for CVDs in Tehran, during 2010 and 2011. The diagnosis of heart failure was established by a cardiologist who was an expert in heart failure and transplantation based on the clinical history and physical examination taking into account the Framingham criteria (Table 1) and Transthoracic Echocardiography (TTE). Diagnosis was established by the existence of at least two major criteria, or one major and two minor criteria and all of them were symptomatic at rest (NYHA/CCS class of IV).

The exclusion criteria were the existence of a positive history of prior admission due to heart failure in any hospitals, having any of the following conditions (acute renal failure, acute pulmonary diseases, cancer, or any other fatal diseases), or lost to follow-up. In addition, patients who moved to other hospitals during the follow-up period were also excluded from the study.

The interviewers fully briefed patients on the purposes of the study. All patients who met the inclusion criteria completed a written consent form. All essential data on the patients were recorded in a designed checklist. Data were collected through either a face-to-face interview or from patients' hospital files classified into three categories including demographic information, potential confounding variables, and information about the patients' SES.

Standard TTE study was performed for all patients by only one cardiologist with a General Electronic (GE) Vivid 3 system
(Horten, Norway), equipped with an M3S multi-frequency phased array transducer and tissue doppler imaging facility; the left ventricular global systolic function was evaluated in terms of the ejection fraction. The biplane Simpson method was applied in accordance with the American Society of Echocardiography (ASE) guidelines (11); patients with both reduced and preserved Left Ventricular Ejection Fraction (LVEF) were included.

Potential risk factors were recorded which were gender, age ( $<75$ and $>75$ years old), marital status, and Body Mass Index (BMI in two categories, normal $<25$ and overweight-obese $>25$ ). Marital status was defined into 2 categories including married and single (included separated and widows). Hypertension was defined as blood pressure higher than $140 / 90 \mathrm{mmHg}$ or the taking of antihypertensive medications. Diabetic status was determined with fasting blood sugar higher than $126 \mathrm{mg} / \mathrm{dl}$ or taking medication or a positive medical history of diabetes. Dyslipidaemia was defined as abnormal lipid profiles, taking medication, or positive medical history of dyslipidaemia. In a self-report process, we asked about medication and physical activity adherence defined by the patient's adherence with physicians' instructions and treatment advices and adherence to recommended physical activity, respectively. Abnormal ejection fraction $(<40 \%)$, cigarette smoking (current smoker vs. non-smokers), the history of receiving surgical or non-surgical cardiac interventions were also recorded.

All patients were closely monitored during hospital stay and after discharge based on approved clinical guidelines; all instructions were recorded in patients' records. During the follow-up period of 12 months 'readmission' was checked by phone contact and by checking electronic hospital records. Any sign of exacerbation of the heart failure which led to patients' referral to a specialist and following it hospital admission was occurred even for 24 hours, was considered as readmission.

\section{Selected assets and indicators for socio-economic status score} Household monthly income and expenditure were investigated using a standard questioner, which were classified into three categories of low (176-352 US dollars), medium (352-752 US dollars) and high (more than 752 US dollars). The education level of patients were classified into three categories of illiterate or primary school (less than 6 years of formal education), high school to diploma (6-12 years of formal education) and higher than diploma (any collage degree). Occupational classification was according to the Iranian

Table 1. Framingham criteria ${ }^{1}$ for $\mathrm{CHF}$

\begin{tabular}{lll}
\hline Major criteria & Minor criteria \\
\hline - & Paroxysmal nocturnal dyspnea & Bilateral ankle edema \\
- & Reck vein distention & Nocturnal cough \\
- & Radiographic cardiomegaly & Dyspnea on ordinary exertion \\
- & Acute pulmonary edema & Hepatomegaly \\
- & S3 gallop & - Pleural effusion \\
- & - Hepreased central venous pressure $\left(>16 \mathrm{~cm} \mathrm{H}_{2} \mathrm{O}\right.$ at right atrium) & Decrease in vital capacity by one third from maximum recorded \\
- Weight loss $>4.50 \mathrm{~kg}$ in 5 days in response to treatment & & \\
\hline
\end{tabular}

$\mathrm{CHF}=$ Congestive Heart Failure.

${ }^{1}$ The Framingham Heart Study criteria are 100\% sensitive and 78\% specific for identifying persons with definite CHF. 
standards developed for national census which categorized job into 3 categories: First, professional works such as managers, teachers, engineers. Second, skilled works such as farmers, livestock workers, salespersons. Third, semi-skilled or unskilled works such as workers, drivers). We categorized retired or disabled or jobless persons based on their last job also the home-makers based on their spouse's job.

In addition to this information, patients were asked about the number of people living in their household, their residential area, the number of rooms in their houses, and their assets. Assets included private real estate, the structure and size of living place, the ownership of a car, refrigerator, freezer, television set, telephone, washing machine, dishwasher, microwave, furniture, vacuum cleaner, computer, Internet access, radio, recorder, bath, toilet, cell phone, and the frequency of travelling abroad.

Construction of socio-economic status index by principle component analysis

We calculated a weighted average of the above variables to arrive at a SES score. To find the optimal weights, PCA was applied. Having used principal component analysis with varimax rotation, one dominant factor was generated that accounted for about $70 \%$ of the total variance. Wealth score was calculated based on the generated weights for variables from the first component; then this score was classified into four quartiles to classified patients based on their scores. The first quartile shows the lowest $25 \%$ of all individuals and the fourth quartile shows the top $25 \%$ of patients with the highest SES score. In the models, the forth quartile (richest patients) was considered as reference group.

\section{Statistical analysis}

Chi-Square test was used to compare the baseline risk factors in patients with and without readmission. Stratified Cox proportional hazards models were constructed to determine the risk of readmission in first, second and third quartiles compared with the highest quartile $\left(4^{\text {th }}\right)$. Moreover, the associate of other potential risk factors were assessed in univariate models; those ones with $P<0.200$ were entered in the multivariable stratified Cox regression model. Unadjusted and adjusted Hazard Ratios (HRs) were calculated for each independent variable along with 95\% Confidence Intervals (95\% CI). "Robust variance estimates" are applied to adjust the variances of estimated model coefficients for correlation among recurrent events on the same subject. Population Attributable Fraction (PAF) was calculated for SES quartiles that showed the contribution of each risk factor for the risk of readmission due to CHF. All statistical analyses were carried out using Stata12 (Stata Corp., College Station, TX, USA). $P<0.050$ were considered as statistically significant, and all statistical tests were two-sided.

\section{Results}

\section{Baseline data}

Table 2 shows demographic information and other clinical features of 305 patients (ten patients were excluded totally; 4 patients because of missing data in their follow-up and six patients because of sudden deaths). During our follow-up, 122 patients (40\%) were re-hospitalised at least once. The total number of readmission was 172 .

The abnormal ejection fraction $(P<0.001)$, current smoking $(P=0.006)$, the lack of recommended physical activity $(P<0.001)$, and poor drug adherence $(P<0.001)$ had significant association with the risk of readmission (Table 2$)$. Comorbidities such as hypertension $(P<0.001)$ and diabetes mellitus $(P=0.001)$ were also significant variables.

Moreover, Chi-Square test showed lower income $(P<0.001)$, lower expenditure $(P<0.001)$, lower occupation position $(P<0.001)$, and lower education were significant predictors for readmission risk (Table 3 ).

The main variables that contributed to creation of the SES score in the PCA were monthly income, expenditure, occupation and some of recorded assets which were access to Internet, personal computer, side-by-side refrigerator, and type of car (Table 4).

The association of socio-economic status with the risk of readmission of congestive heart failure patients

Crude HR of readmission in the third, second and first quartiles (versus to the fourth quartile who were the richest patients) were 1.63 (95\% CI= 0.87-3.04), 7.78 (95\% CI=4.39$13.70)$, and 9.57 (95\% CI=5.55-16.50), respectively (Table 5). Females and singles (versus married) as well as suffering from hypertension and diabetes increased the risk of readmission. Other independent significant variables were poor drug adherence, the lack of recommended physical activity, ejection fraction less than $40 \%$, and cigarette smoking (Table 5).

Multivariable Cox regression analysis showed that proportional HRs for readmission of CHF patients in the third, second and first quartile (versus to the fourth quartile) were 1.05 (95\% CI=0.57-1.93), 2.84 (95\% CI=1.62-4.98), and 2.66 (95\% CI=1.51-4.66), respectively (Table 5). Compared to the crude HR, the adjusted HRs for the first and second quartiles declined around 3.60 and 2.70 times respectively; however, for the third quartile the change was not considerable (Figure 1).

Other potential risk factors in the multivariable model were poor drug adherence $(\mathrm{HR}=2.86,95 \% \mathrm{CI}=2.01-4.07)$, poor physical activity $(\mathrm{HR}=2.35,95 \% \mathrm{CI}=1.41-3.93)$, abnormal ejection fraction $(\mathrm{HR}=3.03,95 \% \quad \mathrm{CI}=1.74-$ 5.28), and concurrent hypertension $(\mathrm{HR}=1.63,95 \%$ $\mathrm{CI}=1.04-2.57, P=0.033)$.

PAF of readmission in the below average SES scores compared to the above average was $54 \%(95 \% \mathrm{CI}=0.36-0.67)$. It means that possibly $54 \%$ of readmission might be prevented in $\mathrm{CHF}$ patients if their SES increased to above average. The adjusted PAF of readmission for drug and physical activity adherence increased to $71 \%$. The median survival time of readmission was 218 and 221 in the second and first quartiles of SES, respectively.

Discussion

This study showed that readmission was around $40 \%$ amongst patients with CHF. The main finding of this study concluded that lower SES is an independent, strong predictive risk factor for readmission risk in CHF patients; in other words, those with a lower educational level, lower income, lower job, and lower score based on their assets, were shown to experience more re-hospitalisation. Other variables such as abnormal 
Table 2. Comparison of demographic characteristics and risk factors of 305 CHF patients according to readmission status, Tehran, 2010-1

\begin{tabular}{|c|c|c|c|}
\hline & Admitted within 12 months $(n=122)$ & Not admitted within 12 months $(n=183)$ & $P$ \\
\hline Gender & & & 0.084 \\
\hline Male & $68(55.74)$ & $120(65.57)$ & \\
\hline Female & $54(44.26)$ & $63(34.43)$ & \\
\hline Age & & & 0.204 \\
\hline$<75$ years & $49(40.16)$ & $87(47.54)$ & \\
\hline$>75$ years & $73(59.84)$ & $96(52.46)$ & \\
\hline Marital status & & & 0.011 \\
\hline Married & $93(76.23)$ & $160(87.43)$ & \\
\hline Single & $29(23.77)$ & $23(12.57)$ & \\
\hline BMI $\left(\mathrm{kg} / \mathrm{m}^{2}\right)$ & & & 0.365 \\
\hline$<25$ (Normal) & $53(43.44)$ & $70(38.25)$ & \\
\hline$\geq 25$ (Overweight/Obese) & $69(56.56)$ & $113(61.75)$ & \\
\hline \multicolumn{4}{|l|}{ Positive History } \\
\hline Cardiac interventions & $59(48.36)$ & $80(43.72)$ & 0.425 \\
\hline Family history of CHD & $52(42.62)$ & $67(36.61)$ & 0.292 \\
\hline \multicolumn{4}{|l|}{ Comorbidity } \\
\hline Dyslipidemia & $115(94.26)$ & $163(89.07)$ & 0.118 \\
\hline Hypertension & $104(85.25)$ & $71(38.80)$ & $<0.001$ \\
\hline Diabetes mellitus & $66(54.10)$ & $63(34.43)$ & $<0.001$ \\
\hline Cigarette status & & & 0.006 \\
\hline No smoking & $55(45.80)$ & $112(61.20)$ & \\
\hline Current smoking & $67(54.92)$ & $71(38.80)$ & \\
\hline Ejection fraction (<40\%) & $111(90.98)$ & $97(53)$ & $<0.001$ \\
\hline \multicolumn{4}{|l|}{ Poor adherence } \\
\hline Drug & $84(68.85)$ & $22(12.02)$ & $<0.001$ \\
\hline Physical activity & $100(81.97)$ & $40(21.86)$ & $<0.001$ \\
\hline Diet & $86(70.49)$ & $131(71.58)$ & 0.836 \\
\hline
\end{tabular}

$\mathrm{CHF}=$ Congestive Heart Failure; $\mathrm{CHD}=$ Coronary Heart Disease

Table 3. Classical SES characteristics of 305 CHF patients and readmission status, Tehran, 2010-1

\begin{tabular}{|c|c|c|c|}
\hline Variable & Admitted within 12 months $(n=122)$ & Not Admitted within 12 months $(n=183)$ & $\boldsymbol{P}$ \\
\hline Income level & & & $<0.001$ \\
\hline Low & $84(68.85)$ & $27(14.75)$ & \\
\hline Medium & $25(20.49)$ & $105(57.38)$ & \\
\hline High & $13(10.66)$ & $51(27.87)$ & \\
\hline Expenditure level & & & $<0.001$ \\
\hline Low & $81(66.39)$ & $32(17.49)$ & \\
\hline Medium & $14(11.48)$ & $35(19.13)$ & \\
\hline High & $27(22.13)$ & $116(63.39)$ & \\
\hline Education level & & & $<0.001$ \\
\hline Illiterate/primary & $91(74.59)$ & $68(37.16)$ & \\
\hline High school & $25(20.49)$ & $71(38.80)$ & \\
\hline University degrees & $6(4.92)$ & $44(24.04)$ & \\
\hline Occupation position & & & $<0.001$ \\
\hline First (Professional) & $29(23.70)$ & $83(45.36)$ & \\
\hline $2^{\text {th }}$ (Skilled workers) & $55(45.08)$ & $78(42.60)$ & \\
\hline $3^{\text {th }}$ (Semi-skilled/unskilled) & $38(31.15)$ & $22(12.02)$ & \\
\hline
\end{tabular}

$\mathrm{SES}=$ Socio-economic Status; $\mathrm{CHF}=$ Congestive Heart Failure

ejection fraction $(<40 \%)$, poor physical activity, poor drug adherence, and hypertension were found to be independent predictive variables as well. Also, our findings addressed that around $54 \%$ of readmissions among CHF patients were attributed to their lower SES. On the other hand, having analysed the hazard ratios in different SES quartiles, it was found that the decrease in the adjusted hazard ratio compared to the crude results was substantial in the first and second quartiles but it was not obvious in the third quartile which means the other unknown predictors for readmission may be existed in the third and fourth quartiles.

Several factors have caused CHF to stand out amongst the most common diseases resulting in readmission. Some studies have estimated that readmission due to CHF during one year follow-up was around $35 \%$ to $40 \%(4,12)$. As seen in this study, almost $40 \%$ of all patients had readmission during the first 12 months follow-up, which was consistent with the others' findings. The results of the present study have also suggested that low SES would significantly increase the risk of readmission. This relationship was evaluated in several 
Table 4. HR of $305 \mathrm{CHF}$ readmission according to SES quartiles and risk factors with Cox regression, crude and adjusted model, Tehran, 2010-1

\begin{tabular}{|c|c|c|c|c|}
\hline \multirow{2}{*}{ Variables } & \multicolumn{2}{|c|}{ Crude model } & \multicolumn{2}{|c|}{ Adjusted model } \\
\hline & $\mathrm{HR}(95 \% \mathrm{Cl})$ & $P$ & $\mathrm{HR}(95 \% \mathrm{Cl})$ & $\boldsymbol{P}$ \\
\hline \multicolumn{5}{|l|}{ SES variable* } \\
\hline $4^{\text {th }}$ quartile (the highest, ref) & Ref & - & Ref & - \\
\hline $3^{\text {rd }}$ quartile & $1.63(0.87-3.04)$ & 0.124 & $1.05(0.57-1.93)$ & 0.852 \\
\hline $2^{\text {nd }}$ quartile & $7.78(4.39-13.70)$ & $<0.001$ & $2.84(1.62-4.98)$ & $<0.001$ \\
\hline $1^{\text {st }}$ quartile (the lowest) & $9.57(5.55-16.50)$ & $<0.001$ & $2.66(1.51-4.66)$ & $<0.001$ \\
\hline \multicolumn{5}{|l|}{ Age } \\
\hline$<75$ years & Ref & - & - & - \\
\hline$>75$ years & $1.31(0.94-1.79)$ & 0.245 & - & - \\
\hline Female gender* & $1.32(0.97-1.79)$ & 0.073 & $1.14(0.81-1.62)$ & 0.433 \\
\hline Single marital status* & $1.65(1.18-2.30)$ & $<0.001$ & $1.12(0.80-1.59)$ & 0.485 \\
\hline \multicolumn{5}{|l|}{ BMI } \\
\hline$<25$ (normal) (ref) & Ref & - & - & - \\
\hline$\geq 25$ (overweight/obese) & $1.16(0.86-1.57)$ & 0.325 & - & - \\
\hline Ejection fraction $<40 \% *$ & $6.03(3.20-11.09)$ & $<0.001$ & $3.03(1.74-5.28)$ & $<0.001$ \\
\hline Current smoker* & $1.50(1.11-2.02)$ & 0.007 & $1.11(0.79-1.55)$ & 0.524 \\
\hline \multicolumn{5}{|l|}{ Poor adherence } \\
\hline Drug* & $6.37(4.41-9.21)$ & $<0.001$ & $2.86(2.01-4.07)$ & $<0.001$ \\
\hline Physical activity* & $5.66(3.35-9.56)$ & $<0.001$ & $2.35(1.41-3.93)$ & $<0.001$ \\
\hline Diet & $1.20(0.87-1.65)$ & 0.264 & - & - \\
\hline \multicolumn{5}{|l|}{ Positive history } \\
\hline Family history of CHD & $1.13(0.84-1.51)$ & 0.402 & - & - \\
\hline Surgical/non-surgical cardiac interventions & $1.02(0.76-1.38)$ & 0.846 & - & - \\
\hline \multicolumn{5}{|l|}{ Comorbidity } \\
\hline Hypertension* & $4.12(2.38-7.13)$ & $<0.001$ & $1.63(1.04-2.57)$ & 0.033 \\
\hline Diabetes mellitus* & $1.65(1.22-2.24)$ & 0.001 & $1.01(0.74-1.38)$ & 0.935 \\
\hline Dyslipidemia & $1.48(0.75-2.91)$ & 0.249 & - & - \\
\hline
\end{tabular}

$\mathrm{HR}=$ Hazard Ratio; $\mathrm{CHF}=$ Congestive Heart Failure; SES= Socio-economic Status; $\mathrm{Cl}=$ confidence interval; $\mathrm{BMI}=\mathrm{Body}$ mass index; $\mathrm{CHD}=$ Coronary Heart Disease

*These variables had p-value of less than 0.20 in crude analysis and only these variables entered to adjusted analysis model.

previous studies; almost all of papers expressed that SES was a strong predictive factor for readmission (13-15).

This raises the question of how low SES would increase the risk of readmission among Iranian CHF patients. Skodova et al. (16) demonstrated that those cardiac patients with lower SES (education and income) had the worse situation in terms of psychological well-being, low quality of life and mental health status compared to those who had a higher SES; it is possibly because of differences in receiving healthcare and treatment services. Studies have shown that people with low SES cannot afford necessary drugs or healthcare services (17). A study conducted by Pell et al. (18) established that individuals with CAD and low SES received less surgical cardiac interventions despite the acute condition of their disease.

In addition, those with low SES had more risk factors associated with readmission including higher blood pressure (19), uncontrolled diabetes, lower physical activity and poorer diet. Bahonar et al. showed that educated women were at lower risk of diabetes compared to women with less education level (7).

Struthers et al. (20) showed that patients with heart failure and low SES experienced more readmissions compared to those with higher SES; such a difference was independent from the severity of the disease. They explained that this difference was probably due to the limited healthcare services for heart failure patients in the deprived areas where people with lower
SES usually live. In other respect, people who lived in these areas did not trust the existed services and travelled to better equipped hospitals.

Moreover, people with lower SES are more exposed to social stressors (21), lower educational status, income and monthly costs, and other problems such as insufficient space to rest at home. In this study, with respect to certain conditions, illiterate patients or those with primary education were more exposed to the risk of readmission compared to those with academic education. One of the main factors is the effect of education on self-care behaviour and its association with food behaviour and diet adherence (22). In other words, illiterate patients are less oriented regarding the importance of drug instruction or diet and physical activity adherence, in order to consult their physicians, compared to those with higher educational status. One study conducted in Iranian haemodialysis patients to evaluate the factors which influence their adherence to dietary and fluid restrictions; they also concluded patient's education levels were associated with fluid adherence positively (23). Such a finding was also noted in some other studies in Iran (24).

The CHF patients are normally recommended to adjust their eating regimes and physical activities. They are also suggested to take multiple drugs and have frequent followup visits. Undoubtedly, the patients need continuous support both mentally and financially. Some studies have shown that readmission in $\mathrm{CHF}$ is partly due to exacerbation of 
Table 5. PCA for component 1 with varimax rotations for $305 \mathrm{CHF}$ patients, Tehran, 2010-1

\begin{tabular}{lc}
\hline Variable & Component 1 \\
\hline Number of room & 0.28 \\
Side by side refrigerator & 0.29 \\
Dish machine & 0.28 \\
Microwave & 0.27 \\
Computer & 0.30 \\
Type of car & 0.29 \\
Going abroad & 0.27 \\
Access to internet & 0.30 \\
Income & 0.33 \\
Expenditure & 0.33 \\
Job & 0.32 \\
\hline PCA= Principle Component Analysis; CHF= Congestive Heart Failure
\end{tabular}

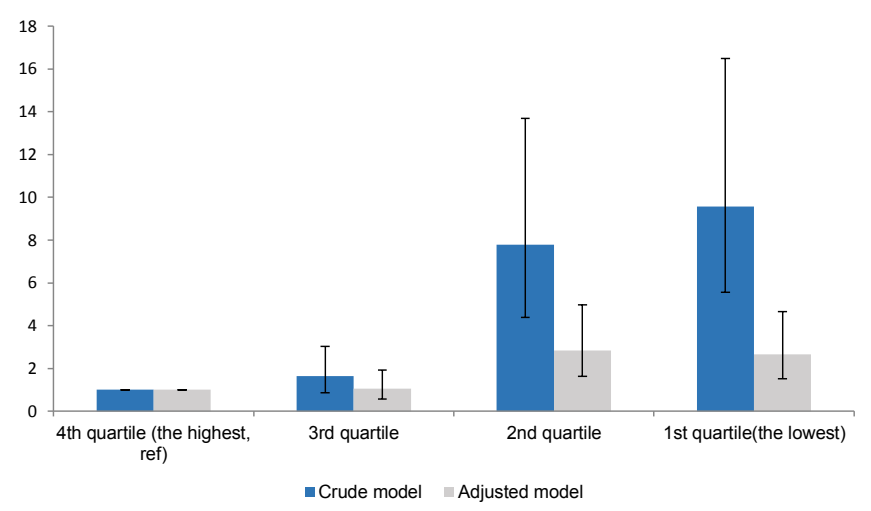

Figure 1. Crude and adjusted HR of readmission of CHF in SES quartiles

the disease's symptoms that could result from patients' nonadherence in taking drugs and following diet instructions recommended by the treatment team $(25,26)$; this is in accordance with the results of the present study.

Moreover, some of the non-adherence of medical treatment can be explicated by age, gender and marital status. Older patients who live alone do not access to family care in order to control their disease; such idea is consistent with one study in HIV positive patients in Iran (27). In the present study, older people, female gender and single patients are significant predictors of readmission in univariate model. There are some evidences that illustrated women are more likely to be readmitted due to CHF (28); it is possible that female patients receive family care less than men or may be women are more sensitive about their health and seek care more than men. However, in the present study adjusted HRs for smoking, diabetes and these 3 factors were not significant after adjustment which means that most of the impact of these factors might be explained by the other factors.

In our multivariate model, some of the independent variables might play the role of intermediate variables partially, such as comorbidities and health behaviors. Therefore, by comparing the crude and adjusted coefficients, we may indirectly evaluate the residual impact of SES on the risk of readmission beyond the pathways which might be explained by other variables in our model.

Generally speaking, the use of educational level as an indicator of SES is common mainly because its interpretation is very easy and similar in both low- and high-income countries (29). However, educational status is affected by birth cohort and its measurement is individualistic, since the added value of the educational status of other members of the family on that particular individual is ignored (30).

The level of family expenditure and income are highly correlated but their concepts are different, therefore replacement of these two measures is not easily (31). The monthly expenditure and payments of families are more or less stable over the fluctuations of income in short term especially in developing countries (32). However, it is a complicated task to collect required information using standard questioners. As a result, the evaluation of assets was recommended as an alternative approach which might help to classified subjects in low- and high-income categories (33). In the case of using as many variables related to SES as possible, it can reveal the multiple domains of SES and provide a better description of it $(34,35)$.

The explanation of our findings should take certain limitations into consideration. Firstly, it was conducted on only one referral centre for heart failure in Tehran and the results could not be generalized. Secondly, some post discharge factors including patients' quality of life, home care, and follow-up visits which could affect the risk of readmission were not assessed. Finally, we know that mortality is considered to be a competing risk for influencing the risk of readmission; however, the number of sudden deaths in this study was low (only six cases) and in addition we were unable to define the exact time of death to evaluate its impact on our conclusion.

To summarise, the results of this study showed that lower SES independently and strongly increased the risk of readmission due to CHF. In particular, the risk of readmission among the first quartile, with the lowest SES, was substantially higher than the other groups even after adjusting for other factors; this means that the association between SES and readmission is not linear, i.e. the risk of readmission in very poor people increases exponentially. This study also suggests that applying some plans in vulnerable groups and conducting some education interventions to optimize the patient's awareness of drug and diet adherence would be useful in further decreasing of readmission due to $\mathrm{CHF}$.

\section{Ethical issues}

The ethical committee of Kerman University of Medical Sciences approved the present study and its protocol.

\section{Competing interests}

The authors declare that they have no competing interests.

\section{Authors' contributions}

Developing the main concept of the research: $\mathrm{AN}, \mathrm{AAH}$; designing the research: $\mathrm{AAH}, \mathrm{AN}, \mathrm{MRB}$; data collection: AN, MS; data analysis: AN, AAH, MRB, MS; interpreting the results: $A A H, A N, N N, H B, M S$; Drafting the manuscript: $A N$, AAH, MS, MRB; answering to the reviewers: AN, AAH, MS, MRB, NN. All authors have read and approved the content and the authorship of the final version of the submitted manuscript.

\section{Authors' affiliations}

${ }^{1}$ Research Center for Modelling in Health, Institute for Futures Studies in Health, Kerman University of Medical Sciences, Kerman, Iran. ${ }^{2}$ Non-Communicable Diseases Research Center, Endocrinology and Metabolism population sciences 
Institute, Tehran University of Medical Sciences, Tehran, Iran. ${ }^{3}$ Regional Knowledge Hub, and WHO Collaborating Centre for HIV Surveillance, Institute for Futures Studies in Health, Kerman University of Medical Sciences, Kerman, Iran. ${ }^{4}$ Cardiac Electrophysiology Research Center, Rajaee Cardiovascular Medical and Research Center, Tehran University of Medical Sciences, Tehran, Iran. ${ }^{5}$ Cardiac Intervention Research Center, Rajaee Cardiovascular, Medical and Research Center, Tehran University of Medical Sciences, Tehran, Iran.

\section{References}

1. Ho KKL, Pinsky JL, Kannel WB, Levy D. The epidemiology of heart failure: the Framingham Study. J Am Coll Cardiol 1993; 22: A6-13. doi: 10.1016/0735-1097(93)90455-a

2. Philbin EF, Rocco TA, Lindenmuth NW, Ulrich $\mathrm{K}$, Jenkins $P L$. Clinical outcomes in heart failure: report from a community hospital-based registry. Am J Med 1999; 107: 549-55. doi: 10.1016/s0002-9343(99)00309-5

3. Berry C, Murdoch DR, McMurray JJ. Economics of chronic heart failure. Eur J Heart Fail 2001; 3: 283-91. doi: 10.1016/s13889842(01)00123-4

4. Cowie M, Fox K, Wood D, Metcalfe C, Thompson S, Coats A, et al. Hospitalization of patients with heart failure. A population-based study. Eur Heart J 2002; 23: 877. doi: 10.1053/euhj.2001.2973

5. Sarraf-Zadegan N1, Boshtam M, Malekafzali H, Bashardoost $N$, Sayed-Tabatabaei FA, Rafiei $M$, et al. Secular trends in cardiovascular mortality in Iran, with special reference to Isfahan. Acta Cardiol 1999; 54: 327-33.

6. Adler NE, Newman K. Socioeconomic disparities in health: pathways and policies. Health Aff 2002; 21: 60-76. doi: 10.1377/ hlthaff.21.2.60

7. Bahonar A, Sarrafzadegan N, Kelishadi R, Shirani S, Ramezani $\mathrm{MA}$, Taghdisi $\mathrm{MH}$, et al. Association of socioeconomic profiles with cardiovascular risk factors in Iran: the Isfahan Healthy Heart Program. Int J Public Health 2011; 56: 37-44. doi: 10.1007/ s00038-010-0125-8

8. Galobardes B, Lynch J, Smith GD. Measuring socioeconomic position in health research. Br Med Bull 2007; 81: 21-37. doi: 10.1093/bmb/ldm001

9. Islami F, Kamangar F, Nasrollahzadeh D, Aghcheli K, Sotoudeh M, Abedi-Ardekani B, et al. Socio-economic status and oesophageal cancer: results from a population-based casecontrol study in a high-risk area. Int J Epidemiol 2009; 38: 97888. doi: 10.1093/ije/dyp195

10. Heart Failure Society Of America. Executive summary: HFSA 2006 comprehensive heart failure practice guideline. J Card Fail Feb 2006; 12: 10-38. doi: 10.1016/j.cardfail.2005.12.001

11. Lang RM, Bierig M, Devereux RB, Flachskampf FA, Foster E, Pellikka PA, et al. Recommendations for chamber quantification. Eur J Echocardiogr 2006; 7: 79-108. doi: 10.1016/j. euje.2005.12.014

12. Krumholz HM, Parent EM, Tu N, Vaccarino V, Wang Y, Radford $\mathrm{MJ}$, et al. Readmission after hospitalization for congestive heart failure among Medicare beneficiaries. Arch Intern Med 1997; 157: 99. doi: 10.1001/archinte.1997.00440220103013

13. Haldeman GA, Croft JB, Giles WH, Rashidee A. Hospitalization of patients with heart failure: national hospital discharge survey 1985-1995. Am Heart J 1999; 137: 352-60. doi: 10.1053/ hj.1999.v137.95495

14. Heo S, Lennie TA, Okoli C, Moser DK. Quality of life in patients with heart failure: ask the patients. Heart Lung 2009; 38: 100-8. doi: 10.1016/j.hrtlng.2008.04.002

15. Philbin EF, Dec GW, Jenkins PL, DiSalvo TG. Socioeconomic status as an independent risk factor for hospital readmission for heart failure. Am J Cardiol 2001; 87: 1367-71. doi: 10.1016/ s0002-9149(01)01554-5

16. Skodova Z, Nagyova I, van Dijk JP, Sudzinova A, Vargova $H$, Rosenberger $\mathrm{J}$, et al. Socioeconomic inequalities in quality of life and psychological outcomes among cardiac patients. Int J Public Health 2009; 54: 233-40. doi: 10.1007/s00038-009-7086-9

17. Rosen RC, Contrada RJ, Gorkin L, Kostis JB. Determinants of perceived health in patients with left ventricular dysfunction: a structural modeling analysis. Psychosom Med 1997; 59: 193-
200. doi: 10.1097/00006842-199703000-00012

18. Pell JP, Pell ACH, Norrie J, Ford I, Cobbe SM. Effect of socioeconomic deprivation on waiting time for cardiac surgery: retrospective cohort study. BMJ 2000; 320: 15-9. doi: 10.1136/ bmj.320.7226.15

19. Colhoun HM, Hemingway H, Poulter NR. Socio-economic status and blood pressure: an overview analysis. J Hum Hypertens 1998; 12: 91-110. doi: 10.1038/sj.jhh.1000558

20. Struthers AD, Anderson G, Donnan PT, Macdonald T. Social deprivation increases cardiac hospitalizations in chronic heart failure independent of disease severity and diuretic non adherence. Heart 2000; 83: 12-6. doi: 10.1136/heart.83.1.12

21. Lewis G, Bebbington $P$, Brugha T. Socioeconomic status, standard of living and neurotic disorder. Lancet 1998; 352: 6059. doi: 10.1016/s0140-6736(98)04494-8

22. Roos E, Lahelma E, Virtanen M, Prattala R, Pietinen P. Gender, socioeconomic status and family status as determinants of food behaviour. Soc Sci Med 1998; 46: 1519-29. doi: 10.1016/s01406736(98)04494-8

23. Rambod M, Peyravi H, Shokrpour N, Sareban MT. Dietary and fluid adherence in Iranian hemodialysis patients. Health Care Manag (Frederick) 2010; 29: 359-64. doi: 10.1097/ HCM.0b013e3181fa0691

24. Tavasoli S, Heidarnazhad H, Kazemnejad A. Factors affecting patients' compliance to metered-dose inhaler drugs in two asthma clinics in Tehran, Iran. Iran J Allergy Asthma Immunol 2006; 5: 187-93.

25. Happ MB, Naylor MD, Roe Prior P. Factors contributing to rehospitalization of elderly patients with heart failure. $J$ Cardiovasc Nurs 1997; 11: 75-84. doi: 10.1097/00005082199707000-00008

26. Ghali JK, Kadakia S, Cooper R, Ferlinz J. Precipitating factors leading to decompensation of heart failure. Traits among urban blacks. Arch Intern Med 1988; 148: 2013-6. doi: 10.1001/ archinte.1988.00380090087021

27. Khalili H, Rohani R, Seyedalinaghi S, Hajiabdolbaghi M, DashtiKhavidaki S, Talasaz AH. Adherence to antiretroviral therapy among Iranian HIVIAIDS patients. Curr Clin Pharmacol 2012; 7: 111-5. doi: 10.2174/157488412800228910

28. Guru V, Fremes SE, Austin PC, Blackstone EH, Tu JV. Gender differences in outcomes after hospital discharge from coronary artery bypass grafting. Circulation 2006; 113: 507-16. doi: 10.1161/circulationaha.105.576652

29. Galobardes B, Shaw M, Lawlor DA, Lynch JW, Davey Smith G. Indicators of socioeconomic position (part 1). J Epidemiol Community Health 2006; 60: 7-12. doi: 10.1136/ jech.2004.023531

30. Winch C. The economic aims of education. J Philos Educ 2002; 36: 101-17.

31. Geyer S, Hemstrom O, Peter R, Vagero D. Education, income, and occupational class cannot be used interchangeably in social epidemiology. Empirical evidence against a common practice. $J$ Epidemiol Community Health 2006; 60: 804-10. doi: 10.1136/ jech.2005.041319

32. Howe LD, Galobardes B, Matijasevich A, Gordon D, Johnston $\mathrm{D}$, Onwujekwe $\mathrm{O}$, et al. Measuring socio-economic position for epidemiological studies in low- and middle-income countries: a methods of measurement in epidemiology paper. Int J Epidemiol 2012; 41: 871-86. doi: 10.1093/ije/dys037

33. Galobardes B, Morabia A, Bernstein MS. Diet and socioeconomic position: does the use of different indicators matter? Int $\mathrm{J}$ Epidemiol 2001; 30: 334-40. doi: 10.1093/ije/30.2.334

34. Braveman PA, Cubbin C, Egerter S, Chideya S, Marchi KS, Metzler M, et al. Socioeconomic status in health research: one size does not fit all. JAMA 2005; 294: 2879-88. doi: 10.1001/ jama.294.22.2879

35. Pollack CE, Chideya S, Cubbin C, Williams B, Dekker M, Braveman P. Should health studies measure wealth? A systematic review. Am J Prev Med 2007; 33: 250-64. doi: 10.1016/j.amepre.2007.04.033 